\title{
Reliability and validity of the Wheelchair User's Shoulder Pain Index (WUSPI)
}

\author{
KA Curtis ${ }^{1}$, KE Roach ${ }^{2}$, EB Applegate ${ }^{2}$, T Amar ${ }^{2}$, CS Benbow ${ }^{2}$, TD Genecco ${ }^{2}$ and J Gualano ${ }^{2}$ \\ ${ }^{1}$ Department of Physical Therapy, California State University Fresno, 2345 E. San Ramon Ave., Fresno, \\ CA 93740-0029; ${ }^{2}$ University of Miami School of Medicine, 5915 Ponce de Leon Blvd., 5th floor, Coral Gables, \\ FL 33146, USA
}

\begin{abstract}
Many long term wheelchair users develop shoulder pain. The purpose of this study was to examine the reliability and validity of the Wheelchair User's Shoulder Pain Index (WUSPI), an instrument which measures shoulder pain associated with the functional activities of wheelchair users. This 15 -item functional index was developed to assess shoulder pain during transfers, self care, wheelchair mobility and general activities. To establish test-retest reliability, the index was administered twice in the same day to 16 long term wheelchair users and their scores for the two administrations were compared by intraclass correlation. To establish concurrent validity, the index was administered to 64 long term wheelchair users and index scores were compared to shoulder range of motion measurements. Results showed that intraclass correlation for test-retest reliability of the total index score was 0.99 . There were statistically significant negative correlations of total index scores to range of motion measurements of shoulder abduction $(r=-0.485)$, flexion $(r=-0.479)$ and shoulder extension $(r=-0.304)$, indicating that there is a significant relationship of total index score to loss of shoulder range of motion in this sample. The Wheelchair User's Shoulder Pain Index shows high levels of reliability and internal consistency, as well as concurrent validity with loss of shoulder range of motion. As a valid and reliable instrument, this tool may be useful to both clinicians and researchers in documenting baseline shoulder dysfunction and for periodic measurement in longitudinal studies of musculoskeletal complications in wheelchair users.
\end{abstract}

Keywords: spinal cord injury; shoulder pain; shoulder pain index; aging; paraplegia; activities of daily living

\section{Introduction}

Individuals who use wheelchairs frequently experience shoulder pain which interferes with functional activities. $^{1-4}$ Functional activities from the wheelchair involve upper extremity weight bearing for transfers, high resistance muscular activity in extremes of range of motion for wheelchair propulsion up inclines, frequent overhead activity and repetitive motion trauma, all of which contribute to the development of shoulder pain. ${ }^{5}$

The Wheelchair User's Shoulder Pain Index (WUSPI) ${ }^{6}$ is a 15 -item self-report index designed to measure shoulder pain during functional activities in wheelchair users. A measurement instrument must be both reliable and valid to provide meaningful information for clinical or research use.

An instrument's reliability establishes the extent to which an instrument or protocol is able consistently to measure the variable being examined. ${ }^{7,8}$ Test-retest reliability measures the degree of reproducibility of results when the instrument is used at two different times. Interrater reliability tests the reproducibility of measurement from one rater to another. Intrarater reliability addresses the reproducibility of results within an individual rater. ${ }^{7,8}$

Validity, in contrast, is the extent to which the instrument measures what it claims to measure. ${ }^{7,8}$ Criterion-referenced validity is measured by comparison of the instrument with another established standard (criterion) of measurement. This type of analysis may be done in a concurrent or predictive type of comparison. ${ }^{8}$

The purpose of the studies presented in this paper was to test the test-retest reliability and concurrent validity of the WUSPI, a self-report functional shoulder pain index for use by wheelchair users.

\section{Method \\ Wheelchair User's Shoulder Pain Index (WUSPI) \\ The WUSPI is a 15-item self-report instrument measur- ing shoulder pain during transfers, wheelchair mobility, self care and general activities. The index demonstrates high internal consistency (Cronbach's alpha $=0.98){ }^{6}$}


The instrument is scored using a visual analog scale, with a minimum score of zero and maximum score of 10 for each of the 15 items. Individual item scores are summed for the total index score. Thus, total index scores can range from zero to 150 .

\section{Reliability study}

To establish test-retest reliability, a convenience sample of 16 long term wheelchair users, 15 males and one female, was recruited from 40 athletes attending a local wheelchair sports event. To participate in the study, subjects met two criteria: (1) they used a wheelchair as their primary means of mobility and (2) they used a wheelchair for at least 1 year prior to the study.

All subjects who met the inclusion criteria and agreed to participate then signed a consent form and were given instructions for completion of the instrument. The 16 subjects who participated in the testretest reliability study were asked to complete the 15 -item instrument during two separate trials on the same day. The researchers were available to answer any questions the subjects might have regarding the wording on the index, but the index was essentially self administered. Index scores for the two administrations of the index were compared by intraclass correlation (ICC $(1,1))$ to establish test-retest reliability.

\section{Validity study}

To establish concurrent validity, a convenience sample of 64 subjects, meeting the above inclusion criteria was drawn from more than 400 athletes attending a wheelchair athletic event for paralyzed veterans. The subjects completed a 38-item pilot WUSPI index. The index scores on this pilot index were subsequently analyzed and 23 items were deleted from the index. ${ }^{6}$ Only the scores on the 15 items which remained in the final index were used to calculate their WUSPI score which was compared with their shoulder range of motion measurements. The identical 15 -items were included in the WUSPI index reported for the reliability study.

We measured the subjects' shoulder range of motion in abduction, flexion, extension, internal and external rotation using an established seated goniometric protocol. We chose to measure shoulder ranges of motion in the wheelchair in a seated position to eliminate any unnecessary transfers or repositioning of the subjects. To ensure that our seated goniometric measurements were reliable, we conducted a pilot study to establish interrater and intrarater reliability for this procedure.

When subjects reported unilateral pain, only the measurements on the shoulder with pain were included for comparison with index scores. Shoulder range of motion measurements of the right and left arms of each subject were averaged together in those subjects who reported pain in both shoulders or reported no shoulder pain. Concurrent validity was assessed by performing a Pearson's correlation between scores on the index and goniometric measurements of shoulder range of motion.

\section{Combined analyses}

The data from the subjects in both the reliability and validity studies were then combined. A total WUSPI score for each subject was recorded. For the subjects in the reliability study, only the scores from the first administration of WUSPI (Time 1) were included. The subjects were then classified by age into one of four age groups. They were classified by years since onset of the disability into one of three wheelchair use groups. A two factor analysis of variance was performed to compare index scores by age and years of wheelchair use.

\section{Results}

\section{Reliability study}

The average age of this sample of 15 men and one woman was 38 years, ranging from 21 to 59 years, with an average of 15 years of wheelchair use. Most (69\%) of these subjects reported spinal cord injury (SCI) as their primary disability, with the remaining subjects reporting polio, lower extremity amputation, spina bifida and other neurological disorders. None of these subjects reported neurological involvement of the upper extremities. Over half $(56 \%)$ of these subjects were employed, $31 \%$ worked as volunteers and the remaining $12 \%$ were students. These subjects spent an average of $22 \mathrm{~h}$ per week in work or school, $11 \mathrm{~h}$ per week in sports and $16 \mathrm{~h}$ per week driving.

Ten of the 16 subjects $(62.5 \%)$ reported current shoulder pain. Of these subjects with current pain, $25 \%$ reported bilateral pain and $38 \%$ reported unilateral pain. Although only two subjects had shoulder pain prior to wheelchair use, almost two-thirds of the subjects reported current elbow or wrist pain.

We analyzed the intraclass correlation (ICC) of individual item and total scores from the first and second administrations of the index. The intraclass correlations ranged between 0.84 and 0.99 on individual items. The total score intraclass correlation was $0.99(P<0.0001)$. These results indicate high testretest reliability of the WUSPI (Table 1).

\section{Validity study}

Sixty two of the 64 subjects were male, with an average age of 43 years, ranging from 23 to 68 years of age. Twenty one subjects were employed, 10 were students, four worked as volunteers and 29 were unemployed or retired. The majority $(90 \%)$ of subjects reported spinal cord injury as their primary disability, with the remainder of the subjects reporting polio, amputation, cerebrovascular accidents, and multiple sclerosis. Of the 57 subjects with SCI, 13 had cervical lesions, 38 had thoracic lesions, and six had lumbar lesions. Subjects averaged 14 years of wheelchair use with a range from 1.5 to 45 years. These subjects reported spending an average of $31 \mathrm{~h}$ per week in work/school activities, $15 \mathrm{~h}$ per week in sport participation and $18 \mathrm{~h}$ per week driving. 
Table 1 Index scores and intraclass correlation to establish test-retest reliability

\begin{tabular}{|c|c|c|c|c|c|}
\hline & \multicolumn{2}{|c|}{ Time 1} & \multicolumn{2}{|c|}{ Time 2} & \multirow[t]{2}{*}{ ICC } \\
\hline & Mean & $S D$ & Mean & $S D$ & \\
\hline \multicolumn{6}{|l|}{ WUSPI index item scores } \\
\hline $\begin{array}{l}\text { Transfers } \\
\text { Bed-wheelchair } \\
\text { Car-wheelchair } \\
\text { Tub/shower-wheelchair } \\
\text { Load wheelchair in car }\end{array}$ & $\begin{array}{l}0.71 \\
0.82 \\
0.98 \\
1.46\end{array}$ & $\begin{array}{l}1.48 \\
1.63 \\
1.97 \\
2.04\end{array}$ & $\begin{array}{l}0.89 \\
0.88 \\
0.85 \\
1.34\end{array}$ & $\begin{array}{l}1.73 \\
1.66 \\
1.66 \\
1.76\end{array}$ & $\begin{array}{l}0.98 \\
0.99 \\
0.97 \\
0.99\end{array}$ \\
\hline $\begin{array}{l}\text { Wheelchair mobility } \\
>10 \text {-min duration } \\
\text { Ramp/uneven }\end{array}$ & $\begin{array}{l}0.90 \\
1.14\end{array}$ & $\begin{array}{l}1.33 \\
1.32\end{array}$ & $\begin{array}{l}0.79 \\
0.93\end{array}$ & $\begin{array}{l}1.13 \\
1.16\end{array}$ & $\begin{array}{l}0.87 \\
0.84\end{array}$ \\
\hline $\begin{array}{l}\text { Self care } \\
\text { Lift object from overhead } \\
\text { Put on pants } \\
\text { Put on T-shirt } \\
\text { Put on button-down shirt } \\
\text { Wash back }\end{array}$ & $\begin{array}{l}1.71 \\
0.38 \\
0.88 \\
0.67 \\
1.02\end{array}$ & $\begin{array}{l}2.65 \\
0.72 \\
1.32 \\
1.53 \\
1.12\end{array}$ & $\begin{array}{l}1.40 \\
0.439 \\
0.84 \\
0.59 \\
1.00\end{array}$ & $\begin{array}{l}2.13 \\
0.81 \\
1.68 \\
1.382 \\
1.37\end{array}$ & $\begin{array}{l}0.95 \\
0.95 \\
0.92 \\
0.99 \\
0.89\end{array}$ \\
\hline $\begin{array}{l}\text { General activities } \\
\text { Work/school activities } \\
\text { Driving } \\
\text { Household chores } \\
\text { Sleeping }\end{array}$ & $\begin{array}{l}1.09 \\
0.57 \\
0.63 \\
1.49\end{array}$ & $\begin{array}{l}1.28 \\
1.54 \\
1.35 \\
2.35\end{array}$ & $\begin{array}{l}1.17 \\
0.58 \\
0.42 \\
1.47\end{array}$ & $\begin{array}{l}1.49 \\
1.66 \\
0.76 \\
2.39\end{array}$ & $\begin{array}{l}0.98 \\
0.99 \\
0.88 \\
0.99\end{array}$ \\
\hline Total score & 14.17 & 18.4 & 13.51 & 17.85 & 0.99 \\
\hline
\end{tabular}

A majority $(73 \%)$ of the subjects reported having current shoulder pain. Of these 47 subjects, 12 had pain in the left shoulder, 12 had pain in the right shoulder and 23 had pain bilaterally. Only 17 subjects reported experiencing no current shoulder pain.

Average active range of motion measurements showed moderate losses in shoulder flexion $\left(149^{\circ}\right)$, abduction $\left(144^{\circ}\right)$ and internal rotation $\left(46^{\circ}\right)$ in these subjects. In contrast, average external rotation and extension measurements showed no limitation. Correlation of total index scores to shoulder range of motion measurements revealed significant negative correlations of shoulder total index scores to measurements of shoulder abduction $(r=-0.49)$, shoulder flexion $(r=-0.48)$ and shoulder extension $(r=-0.30)$. These moderate correlations indicate that subjects who have less available shoulder range of motion have more pain during functional activities, thus supporting concurrent validity of the index (Table 2).

\section{Combined analyses}

The data from the subjects in each of the reliability and validity studies reported above were combined for a series of final analyses. Only the index scores from the first administration of the index in the reliability study were used.

The combined group averaged 42 years of age, with 15 years of wheelchair use (Tables 3 and 4). Total scores for the WUSPI averaged $24.1 \pm 25.5$ in this combined sample, with a range from zero to 88.5. Individual item scores ranged from a mean low score of $1.03( \pm 1.67)$ for pain experienced while putting on pants to a mean high score of $2.20( \pm 2.4)$ for pain

Table 2 Correlation of 15 -item WUSPI index scores to shoulder range of motion measures

\begin{tabular}{lccccccc}
\hline Motion & \multicolumn{9}{c}{ Goniometric measurements } & & \multicolumn{2}{c}{ Correlation to index scores } \\
\cline { 2 - 5 } & $\begin{array}{c}\text { AAOS } \\
\text { Norms }\end{array}$ & Mean & $S D$ & Minimum & Maximum & $r$ & P-value \\
\hline Abduction & 180 & 149 & 27 & 50 & 188 & -0.49 & 0.0001 \\
Flexion & 180 & 144 & 23 & 70 & 185 & -0.48 & 0.0001 \\
Extension & 60 & 77 & 11 & 35 & 98 & -0.30 & 0.0147 \\
External rotation & 90 & 88 & 18 & 9 & 125 & -0.24 & 0.0616 \\
Internal rotation & 70 & 46 & 24 & -30 & 100 & -0.20 & 0.1064 \\
\hline
\end{tabular}

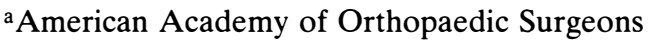


Table 3 Group characteristics and index scores for reliability, validity and combined subject groups

\begin{tabular}{|c|c|c|c|c|c|c|}
\hline & \multicolumn{2}{|c|}{$\begin{array}{c}\text { Reliability study } \\
n=16\end{array}$} & \multicolumn{2}{|c|}{$\begin{array}{c}\text { Validity study } \\
\quad n=64\end{array}$} & \multicolumn{2}{|c|}{$\begin{array}{c}\text { Combined groups } \\
n=80\end{array}$} \\
\hline & Mean & $S D$ & Mean & $S D$ & Mean & $S D$ \\
\hline \multicolumn{7}{|l|}{$\overline{\text { Subject characteristics }}$} \\
\hline $\begin{array}{l}\text { Age } \\
\text { Years of wheelchair use } \\
\text { Hours per week work/school } \\
\text { Hours per week sport participation } \\
\text { Hours per week driving }\end{array}$ & $\begin{array}{l}38.1 \\
15.0 \\
22.1 \\
10.8 \\
15.6\end{array}$ & $\begin{array}{r}12.2 \\
10.0 \\
22.1 \\
5.9 \\
9.4\end{array}$ & $\begin{array}{l}42.8 \\
14.3 \\
30.5 \\
14.8 \\
17.6\end{array}$ & $\begin{array}{r}11.0 \\
8.6 \\
18.8 \\
9.8 \\
12.5\end{array}$ & $\begin{array}{l}41.9 \\
14.5 \\
28.0 \\
14.0 \\
17.1\end{array}$ & $\begin{array}{r}11.3 \\
8.8 \\
19.9 \\
9.2 \\
12.6\end{array}$ \\
\hline \multicolumn{7}{|l|}{ WUSPI index item scores } \\
\hline $\begin{array}{l}\text { Transfers } \\
\text { Bed-wheelchair } \\
\text { Car-wheelchair } \\
\text { Tub/shower-wheelchair } \\
\text { Load wheelchair in car }\end{array}$ & $\begin{array}{l}0.71 \\
0.82 \\
0.98 \\
1.46\end{array}$ & $\begin{array}{l}1.48 \\
1.63 \\
1.97 \\
2.04\end{array}$ & $\begin{array}{l}1.56 \\
2.03 \\
2.11 \\
2.06\end{array}$ & $\begin{array}{l}1.98 \\
2.15 \\
2.19 \\
2.2\end{array}$ & $\begin{array}{l}1.40 \\
1.79 \\
1.88 \\
1.94\end{array}$ & $\begin{array}{l}1.92 \\
2.10 \\
2.19 \\
2.17\end{array}$ \\
\hline $\begin{array}{l}\text { Wheelchair mobility } \\
>10 \text {-min duration } \\
\text { Ramp/uneven }\end{array}$ & $\begin{array}{l}0.90 \\
1.14\end{array}$ & $\begin{array}{l}1.33 \\
1.32\end{array}$ & $\begin{array}{l}1.59 \\
2.30\end{array}$ & $\begin{array}{l}2.06 \\
2.48\end{array}$ & $\begin{array}{l}1.45 \\
2.07\end{array}$ & $\begin{array}{l}1.95 \\
2.34\end{array}$ \\
\hline $\begin{array}{l}\text { Self care } \\
\text { Lift objects from overhead } \\
\text { Put on pants } \\
\text { Put on T-shirt } \\
\text { Put on button-down shirt } \\
\text { Wash back }\end{array}$ & $\begin{array}{l}1.71 \\
0.38 \\
0.88 \\
0.67 \\
1.02\end{array}$ & $\begin{array}{l}2.65 \\
0.72 \\
1.32 \\
1.53 \\
1.12\end{array}$ & $\begin{array}{l}2.32 \\
1.19 \\
1.51 \\
1.24 \\
2.09\end{array}$ & $\begin{array}{l}2.55 \\
1.80 \\
1.96 \\
1.72 \\
2.57\end{array}$ & $\begin{array}{l}2.20 \\
1.03 \\
1.38 \\
1.12 \\
1.87\end{array}$ & $\begin{array}{l}2.57 \\
1.67 \\
1.86 \\
1.69 \\
2.38\end{array}$ \\
\hline $\begin{array}{l}\text { General activities } \\
\text { Work/school activities } \\
\text { Driving } \\
\text { Household chores } \\
\text { Sleeping }\end{array}$ & $\begin{array}{l}1.09 \\
0.57 \\
0.63 \\
1.49\end{array}$ & $\begin{array}{l}1.28 \\
1.54 \\
1.35 \\
2.35\end{array}$ & $\begin{array}{l}1.64 \\
1.40 \\
1.60 \\
2.31\end{array}$ & $\begin{array}{l}1.96 \\
1.82 \\
1.94 \\
2.64\end{array}$ & $\begin{array}{l}1.53 \\
1.23 \\
1.40 \\
2.15\end{array}$ & $\begin{array}{l}1.86 \\
1.79 \\
1.87 \\
2.59\end{array}$ \\
\hline Total score & 14.2 & 18.4 & 26.6 & 26.6 & 24.08 & 25.54 \\
\hline
\end{tabular}

experienced while lifting an object from overhead. Individual item scores for each subject ranged from a low of zero on all items to highs of 8.5 which were scored for individual subjects on items measuring pain experienced while trying to sleep and pain when wheeling up ramps/uneven surfaces. Mean index scores showed that the items which subjects rated the most painful and most difficult included lifting an object from overhead, sleeping, wheeling on ramps/inclines, loading the wheelchair into the car and transferring from tub to wheelchair and washing one's back.

Index score and age, years since of onset of disability To further analyze the effectiveness of the scale in detecting degenerative changes with aging or prolonged wheelchair use, index scores were compared by a 2 factor analysis of variance among subjects grouped by age and years of wheelchair use. Index scores were compared among subjects in four age groups, ages $21-30$ years $(n=14), 31-40$ years $(n=24), 41-50$ years $(n=26)$ and over 50 years of age $(n=15)$ and among subjects in wheelchair use three groups who reported durations of zero to 10 years $(n=32), 11-20$ years $(n=30)$ and over $20(n=17)$ years of wheelchair use.

The results of the 2-factor ANOVA showed significant main effects of age on index score $\left(F_{(3,67)}=6.17\right.$; $P=0.0009)$. The average index score of the 15 subjects over age 50 was over four times as high as the average score of subjects between the ages of 21-30 years. There was also a strong effect of years of wheelchair use on increasing index scores $\left(F_{(2,67)}=2.71 ; P=\right.$ $0.0737)$. The 17 subjects with over 20 years of wheelchair use averaged $8-10$. points higher than the two groups with less exposure.

The interaction effects of age and years of wheelchair use failed to reach statistical significance, yet showed strong trends $\left(F_{(6,67)}=1.57 ; P=0.1697\right)$. The youngest group of subjects (21-30 years) showed low index scores, regardless of years of wheelchair use. Subjects between 31 and 50 years of age generally showed increasing index scores with each increasing increment of 10 years of wheelchair use. In contrast, subjects over 50 seemed to show equally high index scores regardless of the duration of wheelchair use (Figure 1). 
Table 4 Subject characteristics and shoulder pain history for reliability, validity and combined subject groups

\begin{tabular}{|c|c|c|c|c|c|c|}
\hline \multirow[t]{2}{*}{ Subject characteristics } & \multicolumn{2}{|c|}{$\begin{array}{l}\text { Reliability study } \\
\quad n=16\end{array}$} & \multicolumn{2}{|c|}{$\begin{array}{c}\text { Validity study } \\
n=64\end{array}$} & \multicolumn{2}{|c|}{$\begin{array}{c}\text { Combined groups } \\
n=80\end{array}$} \\
\hline & $n$ & $\%$ & $n$ & $\%$ & $n$ & $\%$ \\
\hline \multicolumn{7}{|l|}{ Gender } \\
\hline Male & 15 & 94 & 62 & 97 & 77 & 96 \\
\hline Female & 1 & 6 & 2 & 3 & 3 & 4 \\
\hline \multicolumn{7}{|l|}{ Marital status } \\
\hline Single & 8 & 50 & 24 & 37 & 32 & 40 \\
\hline Married & 4 & 25 & 26 & 41 & 30 & 38 \\
\hline Divorced & 4 & 25 & 11 & 17 & 15 & 19 \\
\hline Separated & 0 & 0 & 3 & 5 & 3 & 4 \\
\hline \multicolumn{7}{|l|}{ Type of disability } \\
\hline SCI & 11 & 69 & 58 & 90 & 68 & 88 \\
\hline Polio & 1 & 6 & 1 & 2 & 1 & 1 \\
\hline Amputation & 1 & 6 & 1 & 2 & 2 & 3 \\
\hline Spina bifida & 1 & 6 & 0 & 0 & 2 & 3 \\
\hline Other & 2 & 13 & 4 & 6 & 4 & 5 \\
\hline \multicolumn{7}{|l|}{ Occupation } \\
\hline Employed & 9 & 56 & 21 & 33 & 30 & 38 \\
\hline Student & 2 & 13 & 10 & 16 & 12 & 15 \\
\hline Volunteer & 5 & 31 & 15 & 23 & 20 & 25 \\
\hline Unemployed & 0 & 0 & 10 & 16 & 10 & 12 \\
\hline Retired & 0 & 0 & 4 & 6 & 4 & 5 \\
\hline Other & 0 & 0 & 4 & 6 & 4 & 5 \\
\hline Currently drives & 16 & 100 & 61 & 95 & 77 & 96 \\
\hline \multicolumn{7}{|l|}{ Type of vehicle } \\
\hline Car & 13 & 81 & 31 & 53 & 44 & 59 \\
\hline Van & 2 & 13 & 17 & 29 & 19 & 26 \\
\hline Other & 1 & 6 & 10 & 17 & 11 & 15 \\
\hline \multicolumn{7}{|l|}{ Pain history } \\
\hline Has current shoulder pain & 10 & 63 & 47 & 73 & 57 & 71 \\
\hline Unilateral & 6 & 38 & 24 & 38 & 30 & 38 \\
\hline Bilateral & 4 & 25 & 23 & 36 & 27 & 34 \\
\hline $\begin{array}{l}\text { Had shoulder problem prior to } \\
\text { wheelchair use }\end{array}$ & 2 & 13 & 4 & 6 & 6 & 8 \\
\hline Has other UE (elbow, wrist) pain & 10 & 62 & 43 & 67 & 53 & 66 \\
\hline
\end{tabular}

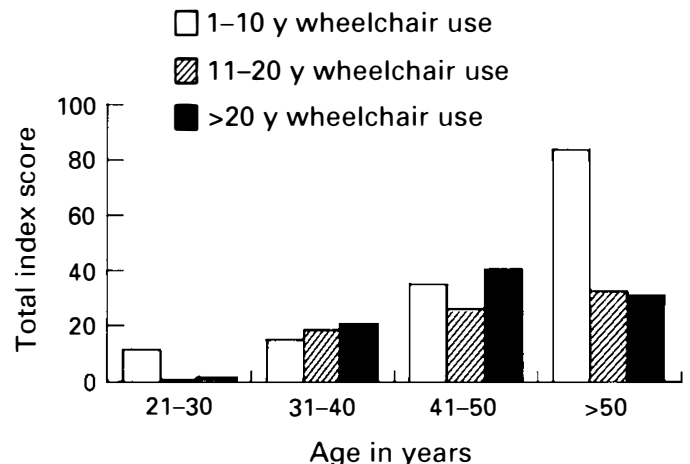

Figure 1 Index scores increased with age but showed a varying relationship to years of wheelchair use within each age group

\section{Discussion}

Test-retest reliability

The results of this study demonstrate high levels of reliability between the two administrations of the index. These findings support the use of this index for multiple administrations over time in clinical use or for longitudinal research designs.

\section{Concurrent validity}

Over $70 \%$ of the subjects in this study reported current shoulder pain. Consistent with other reported findings in the literature, these subjects reported the most intense pain with performing specific functional activities such as wheeling up inclines and reaching over- 
head. Long term wheelchair use has been associated with intraarticular pathology at the shoulder. ${ }^{9}$ We established concurrent validity of the instrument, as total scores on the WUSPI showed a significant negative correlation to shoulder range of motion, indicating decreasing active shoulder range of motion as index pain scores increased.

Although the cross-sectional nature of this study prevents inference, the presence of shoulder pain during functional activity is clearly not synonymous with loss of shoulder range of motion. Even in the strongest correlations (shoulder flexion and shoulder abduction), these goniometric measurements account for only $23.5 \%$ of the variance in the total score on the WUSPI. There are multiple other factors which may influence WUSPI scores such as impingement positioning, decreased strength, overuse, decreased efficiency or deconditioning, in addition to loss of shoulder range of motion. For example, high activity level, indicating possible overuse injury, has been associated with a higher number of soft tissue injuries in wheelchair athletes. ${ }^{10}$ In addition, Burnham et al reported muscle strength imbalance related to impingement syndrome and chronic shoulder pain in wheelchair athletes. ${ }^{5}$

Traditional evaluative measures such as goniometry may have a strong diagnostic value but have a limited relationship to function. This index is better able to quantify the influence of shoulder pain on daily function of wheelchair users than are more general means of measuring shoulder dysfunction. Additionally, the index seems to provide a relevant and practical way to quantify the influence of shoulder pain on functional activities especially when compared with other functional measures that rely on criteria of supervision or assistance to denote functional decline.

\section{Relationship of index scores, age and years of wheelchair use}

The results of this study show a strong relationship of age and a somewhat weaker relationship of years of wheelchair use to increasing index scores. Shoulder pain has been reported to increase in prevalence with advancing age and years of wheelchair use in the SCI population.,11 In this study, this relationship seems to be attenuated in the extremes of young and old subjects. In these youngest and oldest groups, the subject's age, rather than years of wheelchair use appears to have a greater influence.

\section{Limitations of the study}

The data in this study are from a relatively small group of wheelchair users. The primarily male subjects used in this study were wheelchair users attending athletic events. This group may not be representative of the overall population of wheelchair users, and therefore, a broader study is in order. A sample of both male and female wheelchair users, with a wide range of ages, would add to our knowledge in this area.

Additionally, this sample was comprised of individuals with paraplegia and tetraplegia (at level C7 or below) who have full use of their triceps. If used within the population with tetraplegia, the existing questionnaire must be interpreted accordingly as this questionnaire includes activities often not performed independently by individuals with $\mathrm{C} 5$ and $\mathrm{C} 6$ tetraplegia. Further study of the index is indicated to determine the effect on scoring individuals with various levels of tetraplegia.

\section{Directions for future research}

There are many indications for continued use of the WUSPI as a reliable and valid outcome measure for research and clinical practice. The evolution and progression of shoulder pain and related functional deficits of the subjects should be studied longitudinally. Once established, the effects of interventions to prevent shoulder problems such as equipment design, positioning or exercise programs may be studied, using this index as an outcome measure. Finally, the scale may be used as a self-assessment tool by wheelchair users to increase awareness of shoulder dysfunction and encourage them to seek appropriate medical attention.

\section{Conclusion}

The Wheelchair Users Shoulder Pain Index (WUSPI) presented in this paper is a valid and reliable measure of shoulder pain causing limitation of function for individuals who use wheelchairs. The measure can be used clinically for treatment and prevention by assessing shoulder pain during function in wheelchair users. The instrument is also appropriate as an outcome measure in further research to prevent pain and loss of function in the wheelchair using population.

\section{Acknowledgements}

This study was funded in part by the Florida Paralyzed Veterans of America. The authors also acknowledge the support of the Paralyzed Veterans of America (PVA) for permitting us to conduct this study at the 13th National Veterans Wheelchair Games in San Antonio, Texas. The authors would also like to express their appreciation to Rob Voorhees and Amparo Rally for their assistance with manuscript preparation.

\section{References}

1 Gellman H, Sie I, Waters. RL. Late complications of the weight bearing upper extremity in the paraplegic patient. Clin Orthop 1988; 223: $132-135$.

2 Nichols P, Norman PA, Ennis JR. Wheelchair user's shoulder. Scand J Rehabil Med 1979; 11: 29-32.

3 Pentland WE, Twomey LT. The weight bearing upper extremity in women with long term paraplegia. Paraplegia 1991; 29: $521-530$.

4 Waring WP, Maynard FM. Shoulder pain in acute traumatic quadriplegia. Paraplegia 1991; 29: 37-42.

5 Burnham RS, May L, Nelson E, Steadward R, Reid DC. Shoulder pain in wheelchair athletes: The role of muscle imbalance. Am J Sports Med 21: 238-242.

6 Curtis KA et al. Development of the wheelchair user's shoulder pain index. (WUSPI) Paraplegia 1995; 33: 290-293.

7 Jette AM. Concepts in health and methodological issues in 
functional assessment. In Granger DV, Gresham GE (eds). Functional Assessment in Rehabilitation Medicine. Wiliams and Wilkins: Baltimore pp 46-64.

8 Rothstein JM. Measurement and clinical practice: Theory and application. In Rothstein JM (ed). Measurement in Physical Therapy: Clinics in Physical Therapy. Churchill Livingstone: New York, pp 1-46.

9 Bayley JC, Cochran TP, Sledge CB. The weight-bearing shoulder: The impingement syndrome in paraplegics. $J$ Bone Joint Surg Am 1987; 69: 676-678.

10 Curtis KA, Dillon DA. Survey of wheelchair athletic injuries: Common patterns and prevention. Paraplegia 1985; 23: 170-175.

11 Wylie EJ, Chakera TM. Degenerative joint abnormalities in patients with paraplegia of duration greater than 20 years. Paraplegia 1988; 26: 101-106. 